\title{
The tumorigenic, invasive and metastatic potential of epithelial and round subpopulations of the SW480 human colon cancer cell line
}

\author{
WAN-HEE YOON ${ }^{1}$, SANG-KWANG LEE ${ }^{2}$, KYOUNG-SUB SONG ${ }^{2}$, JONG-SEOK KIM ${ }^{2}$, TAE-DONG KIM ${ }^{2}$, \\ GE LI ${ }^{7}$, EUN-JIN YUN ${ }^{2}$, JUN-YOUNG HEO ${ }^{2}$, YEON-JOO JUNG ${ }^{2}$, JONG-IL PARK ${ }^{2}$, GI-RYANG KWEON ${ }^{2}$, \\ SUN-HOE KOO ${ }^{5}$, HAE-DUCK PARK ${ }^{6}$, BYUNG-DOO HWANG ${ }^{2,4}$ and KYU LIM ${ }^{2,3}$ \\ Departments of ${ }^{1}$ Surgery, ${ }^{2}$ Biochemistry, and ${ }^{3}$ Laboratory Medicine, ${ }^{4}$ Cancer Research Institute, ${ }^{5}$ Research Institute \\ for Medical Science, Chungnam National University College of Medicine, 6 Munwha-dong, Joong-gu, \\ Daejeon 301-747; ${ }^{6}$ Dr Park's Breast Clinic, 1126 Dunsan-dong, Seo-gu, Daejeon 302-830, Korea; \\ ${ }^{7}$ Department of General Surgery, Yanbin University Hospital, Yanji 133000, Jilin, P.R. China
}

Received June 9, 2008; Accepted July 14, 2008

DOI: $10.3892 / \mathrm{mmr} 00000026$

\begin{abstract}
It has been reported that the SW480 human colon cancer cell line consists of E-type and R-type cells. The longterm tumorigenic potential, invasive and metastatic properties of these subclones have not been characterized. E-type and R-type cells were subcloned using limiting dilution methods from parental SW480 cells. The cell growth rate was determined by MTT colorimetric assay, and colony forming efficiency was analyzed using Matrigel-coated plates. The activity of matrix metalloproteinase (MMP) and of urokinase plasminogen activator (uPA) was assessed by zymography. Invasive and locomotive ability was analyzed using transwell chambers. In situ apoptosis detection of these subclones was also performed. In vivo long-term tumorigenicity and nodal metastasis were evaluated using nude mice. E-type cells produced spontaneously regressive tumors in spite of invasion and lymph node metastasis. In contrast, R-type cells revealed progressively growing tumors without invasion or metastasis. E-type cells exhibited increased apoptosis and invasive and motile ability, as well as strong MMP-9 and -2 activity. Although phorbol 12-myristate 13-acetate treatment induced MMP-9 activity in E-type cells, it had no effect on R-type cells. These findings suggest that E- and R-type cells may have different biological properties in terms of colon
\end{abstract}

Correspondence to: Dr Kyu Lim or Dr Wan-Hee Yoon (Present Address), Department of Biochemistry, College of Medicine, Chungnam National University, 6 Munwha-dong, Joong-gu, Daejon 301-747, Korea

E-mail:kyulim@cnu.ac.kr; whyoon@cnu.ac.kr

Key words: SW480, E-type and R-type cells, spontaneous regression, invasion, metastasis cancer progression, regression, invasion and nodal metastasis, and might serve as a useful model for these studies.

\section{Introduction}

SW480 human colon cancer cells (ATCC CCL 228) isolated from a Dukes' B colon cancer by Leibovitz et al (1) in 1976 are one of the best characterized colon cancer cell lines (2-10). Tomita et al (11) reported that SW480 cells consist of two distinct subpopulations, which have been designated as E-type (epithelial) and R-type (round). According to the study, R-type cells showed decreased doubling time, loss of contact inhibition, less adhesiveness to culture plates, higher anchorageindependent growth in soft agar, much more aneuploid karyotype, and much larger tumors in nude mice. Subsequently, the authors concluded that R-type cells represent a more malignant variant of the SW480 cells. These findings motivated us to investigate the long-term tumorigenic potential and invasive and metastatic properties of SW480 subclones.

In this study, we demonstrated that E-type cells produce spontaneously regressive primary tumors in nude mice and show frequent capsular invasion and metastasis to axillary lymph nodes. In contrast, R-type cells produce much larger primary tumors in mice without invasion or nodal metastasis, and very weak apoptotic staining of the primary tumor. In addition, these subclones were revealed to have different in vitro invasive potential, motile activity and MMP profiles. These properties of E- and R-type cells may be useful for the study of spontaneous tumor regression, invasion, and lymph node metastasis in human colon cancer.

\section{Materials and methods}

Cell culture and isolation of subpopulations. The SW480 human colon cancer cell line was obtained from American Type Culture Collection (ATCC CCL 228) and maintained as described elsewhere (12). For cell cloning, SW480 cells 
were plated onto 96-well plates at a density of 1 cell/well. After the selection of a single cell in the well, the clones were expanded. The morphology of individual colonies was examined under a phase contrast microscope and two distinct types of colonies were identified and expanded. Finally, three independent colonies of E-type $\left(E_{1}, E_{2}\right.$ and $\left.E_{3}\right)$ cells and three of R-type $\left(R_{2}, R_{3}\right.$ and $\left.R_{5}\right)$ were obtained. Of these, the $E_{3}$ and $R_{2}$ subclones were used.

Growth studies on monolayer cultures and Matrigel. To analyze the growth rates of $\mathrm{E}_{3}$ and $\mathrm{R}_{2}$ cells, $10^{4}$ cells were plated onto each well of 96-well culture plates. From day 2, cells from one set of plates were counted by MTT assay up to day 5 of culture. The time taken for the culture to increase 2-fold in the middle of the exponential phase of growth was determined as the population doubling time.

To evaluate colony forming efficiency on Matrigel (BD Bioscience, Bedford, MA), $200 \mu 1$ Matrigel was transferred into each well of 24-well plates on ice. After the polymerization of Matrigel, cell suspensions $\left(10^{4}\right.$ cells/well) were plated and incubated. After 8 days of culture, the number of colonies in $200 \mathrm{~mm}^{2}$ areas of the plate larger than $0.25 \mathrm{~mm}$ in diameter was counted under a phase contrast microscope. The percent colony forming efficiency (CFE) was determined by the formula as CFE $=$ Number of colonies/Number of cells seeded x $100(12,13)$.

Nude mice tumorigenicity. As previously described (14), exponentially growing cells were harvested by brief trypsinization, washed three times with calcium and magnesiumfree PBS, and resuspended at a final concentration of $5 \times 10^{7}$ cells/ml in serum-free DMEM (SFM). Pathogen-free female BALB/cAnNCrj-nu athymic nude mice (4 weeks old, Charles River Laboratories, Kanazawa, Japan) were anesthetized with diethyl ether by inhalation, and $10^{7}$ cells in $200 \mu 1$ of SFM were inoculated subcutaneously into the right flank. Mice were surveyed regularly, tumors were measured with a caliper, and tumor volumes were determined using the following formula: Volume $=0.5 \times(\text { Width })^{2} \times$ Length .

In situ apoptosis staining. Tissue sections of $\mathrm{E}_{3}$ and $\mathrm{R}_{2}$ primary tumors were stained using the In situ Apoptosis Detection Kit (Oncor; Gaithersburg, MD) according to the manufacturer's instructions.

In vitro invasion and motility assay. Transwell cell culture chambers containing $6.5 \mathrm{~mm}$ diameter polycarbonate filters with $8-\mu \mathrm{m}$ pores (Costar, Cambridge, MA) were used for the previously described assay (14). For the invasion assay, filters coated with basement membrane Matrigel (100 $\mu \mathrm{g} /$ filter) were used. Cells were seeded at a density of $2 \times 10^{5}$ cells/200 $\mu 1$ into the upper chambers. After $72 \mathrm{~h}$ of incubation, cells on the top of the filter generated by non-invasive cells were removed with cotton swabs. The invasive cells beneath the filter were stained with hematoxylin and counted under a microscope (x100). For the motility assay, the same system was used without Matrigel.

Protease analysis by substrate-embedded gel. Proteins in conditioned medium (CM) were separated by electrophoresis
A

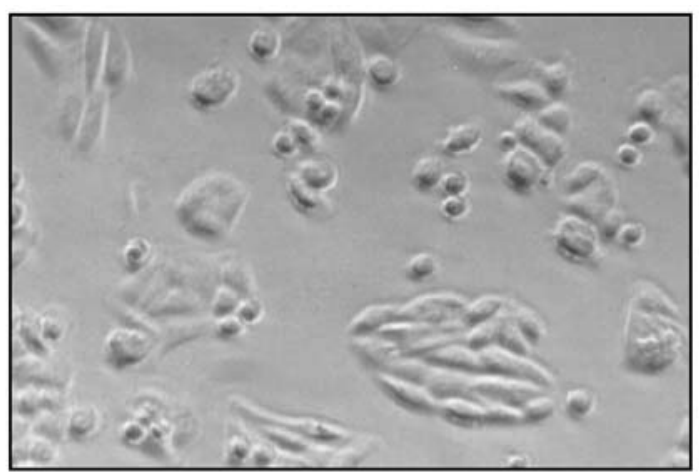

B

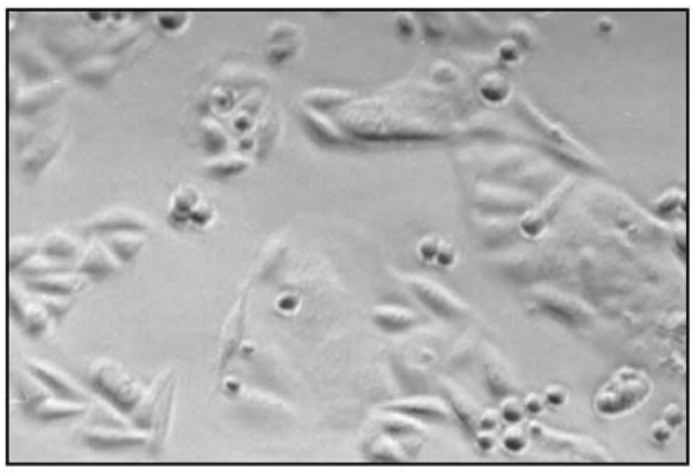

C



Figure 1. Morphologies of the SW480 cell line and its subclone $E_{3}$ and $R_{2}$ cells established with limiting dilution. (A) Parental SW480 cells (x200). (B) $E_{3}$ cells (x200) forming flat epithelial-like cuboidal morphology. (C) $R_{2}$ cells (x200) with a rounded shape growing in clusters of piled-up cells.

in $10 \%$ polyacrylamide gel impregnated with $1 \mathrm{mg} / \mathrm{ml}$ of gelatin (Fisher Chemical Co., Fair Lawn, NJ) or $1 \mathrm{mg} / \mathrm{ml}$ of casein (Sigma Chemical Co., St. Louis, MO) and $13 \mu \mathrm{g} / \mathrm{ml}$ of plasminogen (Sigma Chemical Co.) under non-reducing conditions (14). After electrophoresis, the gels were washed twice in $2.5 \%$ Triton $\mathrm{X}-100$ for $30 \mathrm{~min}$, proteolysed with reaction buffer $(50 \mathrm{mM}$ Tris- $\mathrm{HCl}, 5 \mathrm{mM} \mathrm{CaCl}$, and $0.02 \%$ $\mathrm{NaN}_{3}, \mathrm{pH}$ 8.0) for $72 \mathrm{~h}$ at $37^{\circ} \mathrm{C}$, and stained with Coomassie Blue G-250. To further characterize the proteases, $5 \mathrm{mM}$ 1,10-phenanthroline (Sigma Chemical Co.) as a metalloproteinase (MMP) inhibitor or $5 \mu \mathrm{g} / \mathrm{ml}$ aprotinin (Sigma Chemical Co.) as a serine protease inhibitor was added to the incubation buffer. For the characterization of urokinase plasminogen activator (uPA), $1 \mathrm{mM}$ of amiloride was added to the incubation buffer.

Statistical analysis. Significance of difference between values was assessed using the Kruskal-Wallis test, and all values were expressed as the mean $\pm \mathrm{SD}$. Statistical significance was assigned as $\mathrm{P}<0.05$. 
A

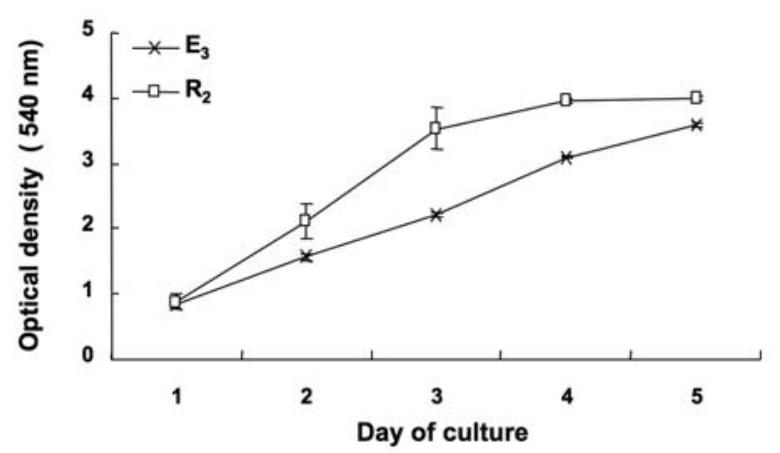

B



Figure 2. Growth studies on monolayer cultures and Matrigel. (A) Proliferation of $E_{3}$ and $R_{2}$ cells. Cells were plated at a density of $10^{4}$ cells/well on 96-well plates and cultured for up to 5 days. After the indicated time of culture, cell numbers were determined by MTT colorimetric assay. Data are the mean $\pm \mathrm{SD}$ of one representative of three repeat experiments. (B) Colony forming efficiency (CFE) on Matrigel. After 8 days of culture, the number of colonies in $200 \mathrm{~mm}^{2}$ areas $>0.25 \mathrm{~mm}$ in diameter was counted in five randomly selected areas per well, and the total number of colonies in a well was determined. All assays were performed in triplicate, and the CFE (\%) was calculated. Data represent the mean $\pm \mathrm{SD}$ of the CFE.

\section{Results and Discussion}

Using a limiting dilution of parental SW480 cells (Fig. 1A), we obtained three independent colonies of E-type subpopulations and three of R-type. Of these, we used $\mathrm{E}_{3}$ and $\mathrm{R}_{2}$ cells as repre- sentative subclones of E- and R-type cells because of their similarity with the E- and R-type cells of Tomita et al. $\mathrm{E}_{3}$ cells exhibited epithelial colonies composed of cells with a cuboidal shape (Fig. 1B). In contrast, $\mathrm{R}_{2}$ cells had a rounded and refractile morphology and were piled up on each other and attached loosely to the plates (Fig. 1C). In the cytogenetic analysis, more complex structural abnormalities were observed in $E_{3}$ cells than in $R_{2}$ cells. However, tetraploidy cells were predominant in $\mathrm{R}_{2}$ tumors (data not shown). These chromosomal characteristics of our subclones were identical to the E- and R-type cells originally described by Tomita et al (11).

It was reported that the doubling times of E- and R-type cells were 31.6 and $15.6 \mathrm{~h}$, respectively, and that the CFE was increased almost 10-fold in R-type cells compared to E-type cells. As shown in Fig. $2 \mathrm{~A}, \mathrm{R}_{2}$ cells grew faster than $\mathrm{E}_{3}$ cells. The doubling times of $E_{3}$ and $R_{2}$ cells, calculated from their respective growth curves, were 25.7 and $22.6 \mathrm{~h}$, respectively. In addition, the $\% \mathrm{CFE}$ of $\mathrm{E}_{3}$ cells was 2.2-fold higher than that of $\mathrm{R}_{2}$ cells (Fig. $2 \mathrm{~B} ; 7.5 \pm 0.4$ versus $3.4 \pm 1.7 \%$; $\mathrm{P}<0.05$ ). It was therefore suggested that E-type cells have a greater ability to colonize than R-type cells. This CFE value differs from that of a previous report (11). We performed the CFE on matrix protein Matrigel, which seems to be more physiological compared to the $0.3 \%$ soft agar used in the previous study. This may have caused the disparate values of CFE.

In order to evaluate their tumorigenic potential, parental $\mathrm{SW} 480, \mathrm{E}_{3}$ and $\mathrm{R}_{2}$ cells were injected subcutaneously in nude mice, and tumor volumes were measured. As shown in Table I, $\mathrm{R}_{2}$ tumors grew very rapidly and continuously up to the time of sacrifice on day 100 . At day 20 , the mean tumor volume produced by the $\mathrm{R}_{2}$ cells was 7.0- and 10.6-fold larger than the tumor volumes produced by the parental SW480 and $\mathrm{E}_{3}$ cells, respectively. These results coincide exactly with those of the original study of Tomita et al (11), with the exception of experimental time. All experimental animals in that study were sacrificed on day 25, precluding the long-term evaluation of tumor volume. In our experiments, the tumor volumes of parental SW480 cells increased very slowly with time up to day 100 . Notably, $\mathrm{E}_{3}$ cells produced very slow-growing tumors, similar to parental SW480 cells up to day 20, and then the tumor volumes decreased to a nearly dormant state from

Table I. Tumorigenicity in nude mice.

\begin{tabular}{|c|c|c|c|}
\hline \multirow[b]{2}{*}{ Days of inoculation } & \multicolumn{3}{|c|}{ Tumor volume $\left(\mathrm{mm}^{3}\right)$} \\
\hline & SW480-parental $(n=5)$ & $E_{3}(n=10)$ & $\mathrm{R}_{2}(\mathrm{n}=10)$ \\
\hline 10 & 44.00 & $35.83 \pm 19.21$ & $94.33 \pm 14.06$ \\
\hline 20 & 63.75 & $42.17 \pm 14.38$ & $445.50 \pm 57.28$ \\
\hline 30 & 52.85 & $19.50 \pm 8.84$ & $896.00 \pm 227.12$ \\
\hline 40 & 53.50 & $2.67 \pm 1.89$ & $1,950.83 \pm 794.48$ \\
\hline 60 & 96.00 & $5.83 \pm 5.66$ & $4,101.67 \pm 944.83$ \\
\hline 80 & 126.00 & $5.83 \pm 5.66$ & $9,310.00 \pm 2,438.72$ \\
\hline 100 & 189.55 & $8.84 \pm 9.30$ & $17,797.33 \pm 2,258.97$ \\
\hline
\end{tabular}

Data represent the mean $\pm \mathrm{SD}$. For experiment details, see Materials and methods. 
A
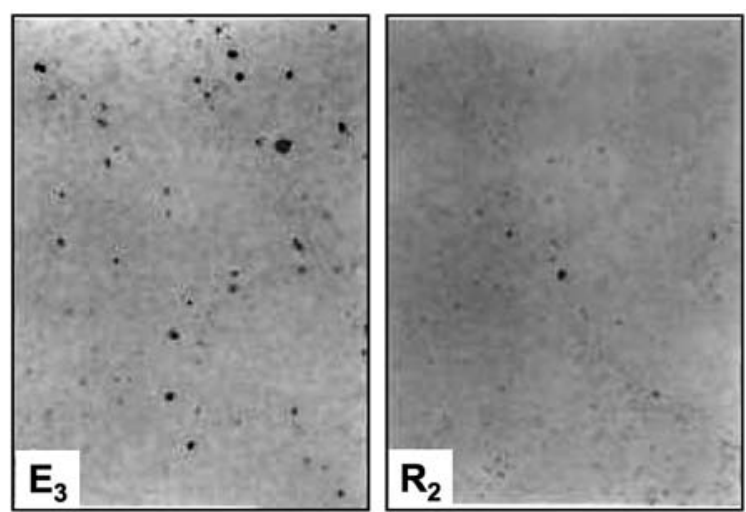

B

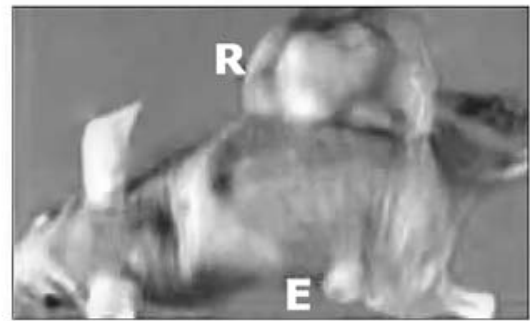

Figure 3. Apoptotic staining of primary tumors produced from $E_{3}$ and $R_{2}$ cells (x100). (A) $\mathrm{R}_{2}$ tumors showed very weak and limited staining of apoptotic cells, whereas $\mathrm{E}_{3}$ tumors showed 4-fold increased staining compared to the $\mathrm{R}_{2}$ tumors. (B) Tumorigenicity of $\mathrm{E}_{3}$ and $\mathrm{R}_{2}$ cells.

day 40 (Fig. 3B). The different tumor growth rates as well as the spontaneous regressive character of these subclones were also observed in severe combined immune deficiency (SCID) mice (data not shown). To determine whether apoptosis plays a role in the regression of $\mathrm{E}_{3}$ tumors, in situ apoptosis detection was performed. The number of apoptotic cells of $E_{3}$ tumors was 4.0-fold higher compared to that of $R_{2}$ tumors (Fig. 3A). These results suggest that the regression of $E_{3}$ tumors may be caused, at least in part, by increased apoptosis in $\mathrm{E}_{3}$ tumors

Histologic examination revealed that pathologic complete tumor regression (pCR) of $\mathrm{E}_{3}$ tumors developed in $50 \%(5 / 10)$ of nude mice. Notably, $80 \%(8 / 10)$ of $E_{3}$ tumors, regardless of pCR, revealed ipsilateral axillary lymph node metastasis (Fig. 4B), and 50\% (5/10) of the $\mathrm{E}_{3}$ tumors that did not show pCR revealed peritumoral capsular invasion (Fig. 4A) in spite of primary tumor regression. $\mathrm{R}_{2}$ tumors did not produce invasive lesions around the primary tumors (Fig. 4C).

The invasive and locomotive ability of $\mathrm{E}_{3}$ and $\mathrm{R}_{2}$ cells has not as yet been studied. The in vitro invasive ability of $\mathrm{E}_{3}$ cells was 26.8-fold higher than that of $\mathrm{R}_{2}$ cells $(26.8 \pm 8.1$ versus $1.0 \pm 0.8$ cells/HPF; $\mathrm{P}=0.0013$; Fig. 5 ). In addition, the in vitro motile activity of $E_{3}$ cells was 19.3 -fold higher than that of $R_{2}$ cells $(90.2 \pm 25.4$ versus $4.7 \pm 1.6$ cells/HPF; $P=0.0007$; Fig. 5$)$. These findings suggest that E-type cells are much more invasive and motile compared to R-type cells.

The key enzymes that have been shown to be closely associated with invasive and metastatic potential are MMPs and uPA (13-15). However, these protease activities have not
A

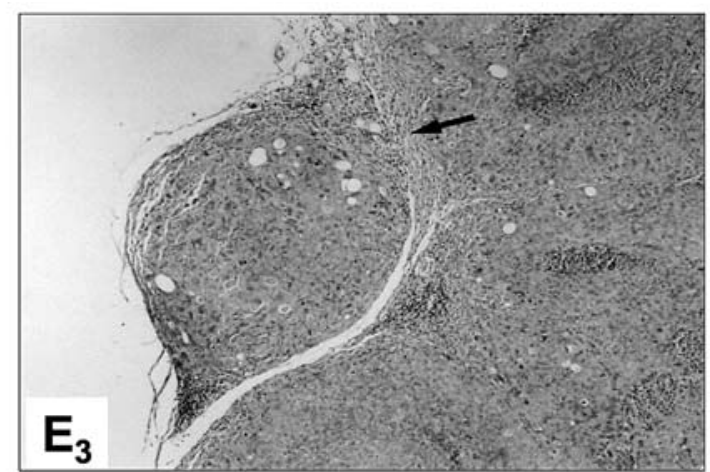

B

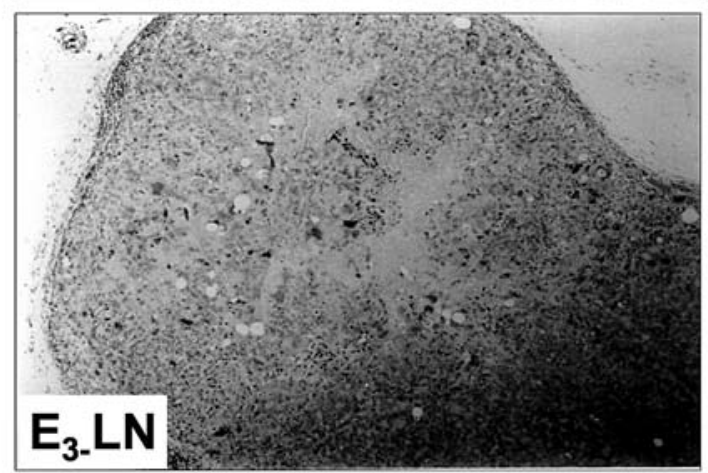

C

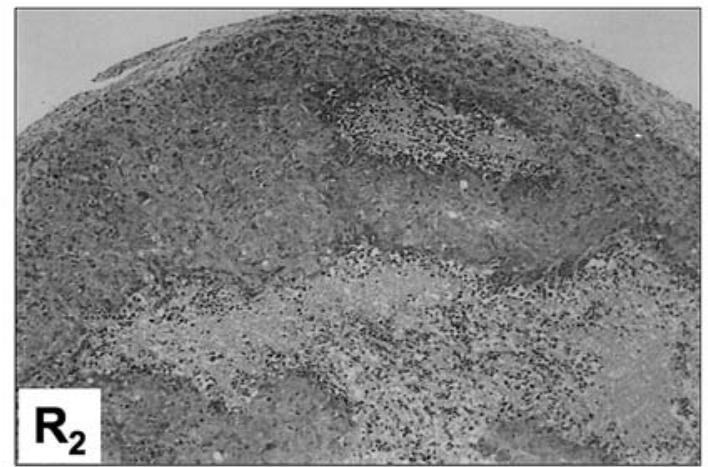

Figure 4. Photomicrographs showing a primary tumor and nodal metastasis of an $E_{3}$ and $R_{2}$ primary tumor in nude mice (x40). (A) A primary tumor of $E_{3}$ cells. The main mass is composed of solid sheets of tumor cells with central necrosis and invades through the capsule, forming a pericapsular satellite tumor nest. (B) Axillary lymph node metastasis observed in nude mice bearing an $E_{3}$ tumor. (C) The $R_{2}$ tumor, which does not produce an invasive lesion around the primary tumor.

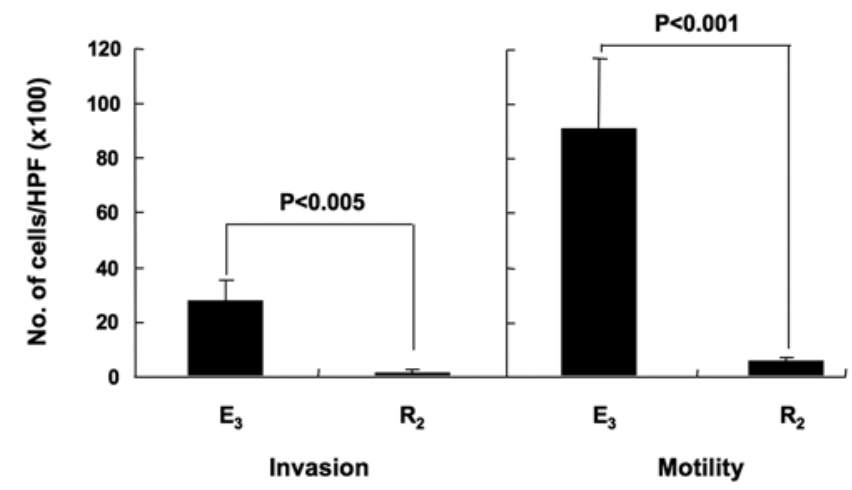

Figure 5. Invasive and motile activities of $\mathrm{E}_{3}$ and $\mathrm{R}_{2}$ cells in vitro. For the invasion assay, filters of the transwell culture chamber were gelatinized by pre-coating with Matrigel. For the motility assay, the same system without Matrigel was used as described in Materials and methods. After counting invasive or motile cells, percentages were normalized to $100 \%$. Values represent the mean $\pm \mathrm{SD}$ of three independent experiments. 
A

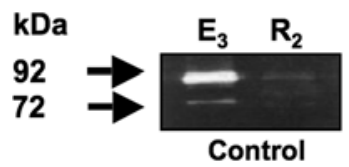

B

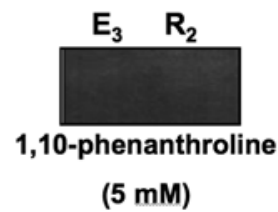

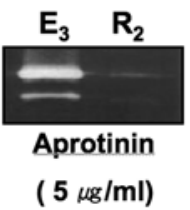

C

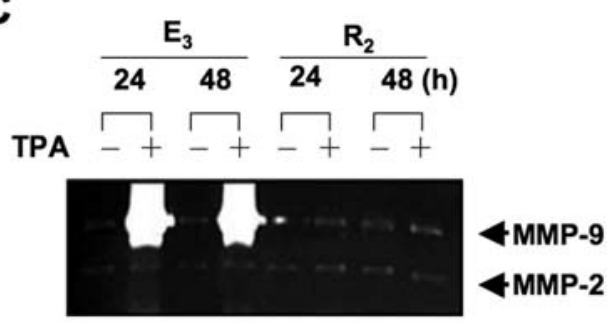

Figure 6. Zymography of MMP-9 and -2 activity in $\mathrm{E}_{2}$ and $\mathrm{R}_{3}$ cells. (A) Protease activity in conditioned medium (CM) normalized for $10^{7}$ cells was measured using gelatin zymography as described in Materials and methods. (B) For the characterization of proteases, the MMP inhibitor 1,10- phenanthroline and the serine protease inhibitor aprotinin were used. The $C M$ of $E_{3}$ cells showed strong MMP-9 and -2 activity compared to $R_{2}$ cells. $(C) E_{3}$ and $R_{2}$ cells were treated with or without TPA $\left(10^{-7} \mathrm{M}\right)$ for the indicated times.

been studied in E- and R-type cells. To investigate the differences in MMP production of these subclones, the MMP activity of the conditioned medium (CM) was measured by substrate-embedded SDS-PAGE. The CM of $\mathrm{E}_{3}$ cells showed strong $92-\mathrm{kDa}$ and relatively weak $72-\mathrm{kDa}$ gelatinolytic activity (Fig. 6A). These gelatinolytic activities were entirely inhibited by the MMP inhibitor 1,10-phenanthroline, but not inhibited by the serine protease inhibitor aprotinin (Fig. 6B). In the present experiment, $\mathrm{E}_{3}$ and $\mathrm{R}_{2}$ cells were treated with $10^{-7} \mathrm{M}$ phorbol 12-myristate 13-acetate (TPA) for 24 and $48 \mathrm{~h}$, and MMP-9 activity was measured. Although TPA induced MMP-9 activity in E-type cells, it had no effect on R-type cells (Fig. 6C). It can therefore be concluded that $\mathrm{E}_{3}$ cells secrete large amounts of MMP-9 and -2 compared to $\mathrm{R}_{2}$ cells, and that E- and R-type cells may have different TPA signaling pathways. We also tested the activity of the plasminogen activator of these cells. The $\mathrm{CM}$ of both $\mathrm{E}_{3}$ and $\mathrm{R}_{2}$ cells showed identical intensity of 55-kDa caseinolytic bands, which was completely inhibited by uPA inhibitor $(1 \mathrm{mM}$ amiloride; data not shown). Consequently, there was no difference in the uPA of these subclones.

Tumor progression is an evolutionary process determined by the generation of heterogeneity and the selection of the variants most suited to survival, growth and invasion (16). It has been demonstrated that genetic and phenotypic instability in cell lines results in heterogeneous cell populations $(17,18)$. This heterogeneity is the basis of malignant potential and contributes to the development of variant cells with different abilities (19). Recently, the presence of high rates of structural chromosomal instability was observed in the SW480 cell line (20). Higher instability rates in subclones compared to parental cells were also demonstrated $(21,22)$. These subclones were obtained from the parental SW480 cells by the limiting dilution technique, regardless of any morphological selection criteria (20-22). Accordingly, our findings are unique in that they indicate that spontaneous regression occurs in $\mathrm{E}_{3}$ tumors in vivo at a high frequency, despite invasion and nodal metastasis. On the other hand, $\mathrm{R}_{2}$ tumors were revealed to have progressive growing properties without invasion or metastasis. We hope that future studies using these subclones may explain the process of clonal selection for progression, regression, invasion and nodal metastasis in colon cancer, and are currently investigating the differential regulation of MMP-9 and -2 by TPA and TNF- $\alpha$ in $E_{2}$ and $R_{3}$ cells.
To summarize, the present study demonstrated that $E_{3}$ and $R_{2}$ cells have different biological properties in terms of their tumorigenicity, invasion and nodal metastasis. These subclones may be useful in the study of colon cancer progression.

\section{Acknowledgements}

This study was funded by the Korean Research Foundation, grant no. KRF-99-041-F00209.

\section{References}

1. Leibovitz A, Stinson JC, McCombs WB III, McCoy CE, Mazur KC and Mabry ND: Classification of human colorectal adenocarcinoma cell lines. Cancer Res 36: 4562-4569, 1976.

2. Quax PH, van Leeuwen RT, Verspaget HW and Verheijen JH: Protein and messenger RNA levels of plasminogen activators and inhibitors analyzed in 22 human tumor cell lines. Cancer Res 50: 1488-1494, 1990.

3. Coffey RJ Jr, Goustin AS, Soderquist AM, et al: Transforming growth factor alpha and beta expression in human colon cancer lines: implications for an autocrine model. Cancer Res 47: 4590-4594, 1987.

4. Anzano MA, Rieman D, Prichett W, Bowen-Pope DF and Greig R: Growth factor production by human colon carcinoma cell lines. Cancer Res 49: 2898-2904, 1989.

5. Pignatelli M and Bodmer WF: Integrin-receptor-mediated differentiation and growth inhibition are enhanced by transforming growth factor-beta in colorectal tumour cells grown in collagen gel. Int J Cancer 44: 518-523, 1989.

6. Capon DJ, Seeburg PH, McGrath JP, et al: Activation of Ki-ras2 gene in human colon and lung carcinomas by two different point mutations. Nature 304: 507-513, 1983.

7. Suarez HG, Nardeux PC, Andeol Y and Sarasin A: Multiple activated oncogenes in human tumors. Oncogene Res 1: 201-207, 1987.

8. Nigro JM, Baker SJ, Preisinger AC, et al: Mutations in the p53 gene occur in diverse human tumour types. Nature 342: 705-708, 1989.

9. Yaseen NY, Watmore AE, Potter AM, Potter CW, Jacob G and Rees RC: Chromosome studies in eleven colorectal tumors. Cancer Genet Cytogenet 44: 83-97, 1990.

10. Nishisho I, Nakamura Y, Miyoshi Y, et al: Mutations of chromosome 5q21 genes in FAP and colorectal cancer patients. Science 253: 665-669, 1991.

11. Tomita N, Jiang W, Hibshoosh H, Warburton D, Kahn SM and Weinstein IB: Isolation and characterization of a highly malignant variant of the SW480 human colon cancer cell line. Cancer Res 52: 6840-6847, 1992.

12. Li G, Kim DH, Kim TD, et al: Protein-bound polysaccharide from Phellinus linteus induces G2/M phase arrest and apoptosis in SW480 human colon cancer cells. Cancer Lett 216: 175-181, 2004. 
13. Dahiya R, Yoon WH, Boyle B, Schoenberg S, Yen TS and Narayan P: Biochemical, cytogenetic, and morphological characteristics of human primary and metastatic prostate cancer cell lines. Biochem Int 27: 567-577, 1992.

14. Yoon WH, Jung YJ, Kim TD, et al: Gabexate mesilate inhibits colon cancer growth, invasion, and metastasis by reducing matrix metalloproteinases and angiogenesis. Clin Cancer Res 10: 4517-4526, 2004

15. Sappino AP, Busso N, Belin D and Vassalli JD: Increase of urokinase-type plasminogen activator gene expression in human lung and breast carcinomas. Cancer Res 47: 4043-4046, 1987.

16. Dexter DL and Leith JT: Tumor heterogeneity and drug resistance. J Clin Oncol 4: 244-257, 1986.

17. Cifone MA and Fidler IJ: Increasing metastatic potential is associated with increasing genetic instability of clones isolated from murine neoplasms. Proc Natl Acad Sci USA 78: 6949-6952, 1981.
18. Kraemer PM, Travis GL, Ray FA and Cram LS: Spontaneous neoplastic evolution of Chinese hamster cells in culture: multistep progression of phenotype. Cancer Res 43: 4822-4827, 1983.

19. Chow M and Rubin H: The cellular ecology of progressive neoplastic transformation: a clonal analysis. Proc Natl Acad Sci USA 96: 2093-2098, 1999.

20. Camps J, Ponsa I, Ribas M, et al: Comprehensive measurement of chromosomal instability in cancer cells: combination of fluorescence in situ hybridization and cytokinesis-block micronucleus assay. FASEB J 19: 828-830, 2005.

21. Ribas M, Masramon L, Aiza G, Capella G, Miro R and Peinado MA: The structural nature of chromosomal instability in colon cancer cells. FASEB J 17: 289-291, 2003.

22. Masramon L, Vendrell E, Tarafa G, et al: Genetic instability and divergence of clonal populations in colon cancer cells in vitro. J Cell Sci 119: 1477-1482, 2006. 